\title{
Dominantly inherited drusen of Bruch's membrane
}

\author{
A. F. DEUTMAN AND L. M. A. A. JANSEN* \\ Eye Hospital, Rotterdam Medical Faculty, Rotterdam
}

Hyaline bodies may be found in the optic disc and in several parts of the retina as a nonspecific finding (Wolter, 1959). The term drusen ("colloid bodies") is usually reserved for large hyaline bodies of the optic disc and Bruch's membrane.

Lorentzen (1966), postulated that drusen of the optic disc had an irregular dominant pattern of inheritance after an examination of the relatives of 49 affected individuals.

Drusen of Bruch's membrane are found in several degenerative conditions and systemic diseases and are often a senile manifestation (Duke-Elder, 1967). Not infrequently, however, they are the result of a primary hereditary dystrophy, usually transmitted as a regular dominant trait.

In spite of their common designation, which is based on the ophthalmoscopic appearance, the histochemical properties of drusen of the optic disc and of Bruch's membrane are somewhat different (Seitz and Kersting, 1962). This is understandable as the former consist of degenerative products of the nerve fibres, and the latter of degenerative products of the retinal pigment epithelium (Seitz, I968).

Hereditary drusen of Bruch's membrane are known by a variety of names such as Tay's central guttate choroiditis, Holthouse-Batten's superficial chorioretinitis, Doyne's honeycomb choroiditis, and malattia leventinese. Franceschetti, François, and Babel (1963) regard hereditary drusen of Bruch's membrane as a single entity, but also recognize the four different types mentioned above; this leads to much confusion. With Waardenburg (1948), Forni and Babel (1962), Franceschetti and others (1963), Krill and Klien (1965), and Duke-Elder ( 1967 ), we think that all dominantly inherited drusen of Bruch's membrane constitute one clinical entity. The three cases described by Hutchinson and Tay ( 1875 ) and the one case reported by Holthouse and Batten (1897) do not represent separate entities, and the differential diagnosis between Doyne's honeycomb choroiditis (Doyne, I899, 1910) and malattia leventinese (Vogt, 1925; Klainguti, 1932) is impossible, as the ophthalmoscopic, functional, histological, and hereditary properties are identical in both conditions (Treacher Collins, 1913; Forni and Babel, 1962; Pearce, 1968). Drusen of Bruch's membrane can thus be divided into the two following categories: degenerative and hereditary.

The hereditary drusen constitute one of the dystrophies of the central retina of which there are several distinct types, including Stargardt's disease, vitelliform dystrophy of the fovea, fundus flavimaculatus, and reticular dystrophy of the pigment epithelium (Sjögren). For this clinical entity we suggest the name "dominant drusen of Bruch's membrane". 
The clinical picture of dominant drusen is variable. All sizes of drusen from small (Fig. I) to large (Fig. 2) have been described (Fuchs, 1956). This dystrophy usually affects both eyes symmetrically and develops between the ages of 20 and 30 years with a few small round white drusen appearing at both posterior poles. These usually increase in number and later in size until late middle age, when the posterior pole is covered with white spots, which may show a mosaic, though the typical honeycomb appearance described by Doyne is often absent. The spots then coalesce and the overlying retina becomes thin and atrophic, while pigmentation and choroidal atrophy become apparent. As a complication retinal haemorrhages may occur. The finding of white colloid bodies on the nasal side of the disc (Fig. 3) may be regarded as virtually pathognomonic of

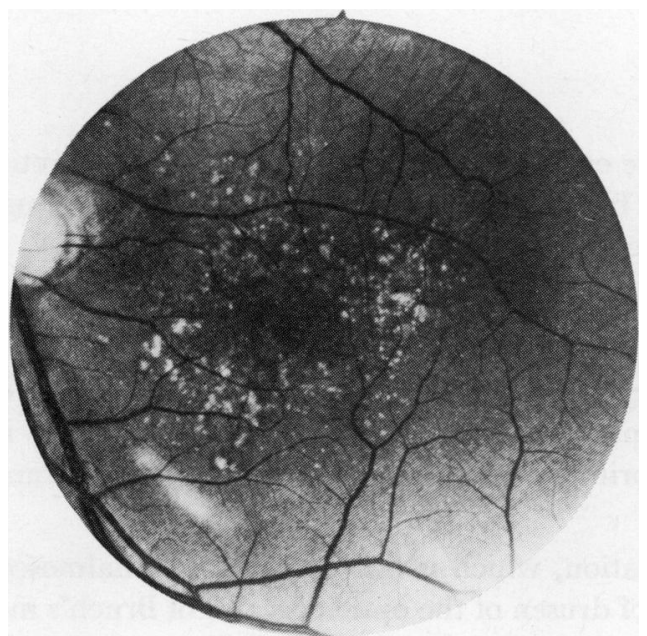

FIG. I Small drusen of Bruch's membrane

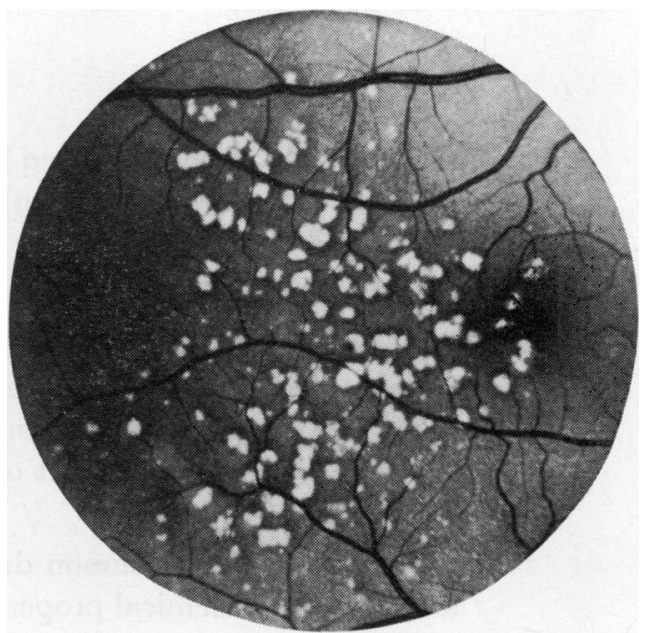

FIG. 2 Rather large drusen of Bruch's membrane

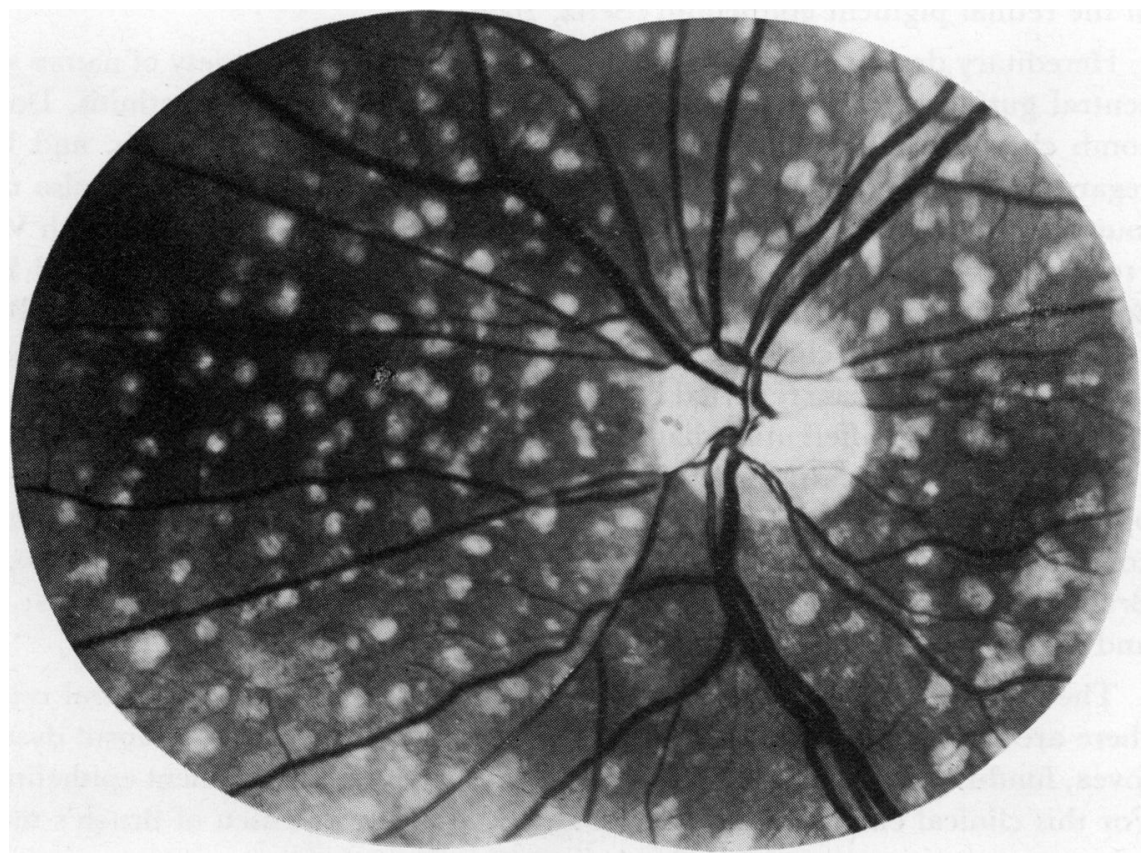

FIG. 3

Drusen surrounding the optic disc 
dominant drusen. In advanced cases almost rectangular patches surrounding the optic disc are a characteristic feature.

The purpose of this paper is to present two families, each with a characteristic ophthalmoscopic pattern. Individuals are not usually affected ophthalmoscopically by this dystrophy before the age of 20 years, but we found dominant drusen in a pair of identical twins and in two boys aged 12 and 14 years.

The two families included ten affected individuals and, apart from two cases reported by Waardenburg (1948), no other cases have been described in the Netherlands.

\section{Case histories}

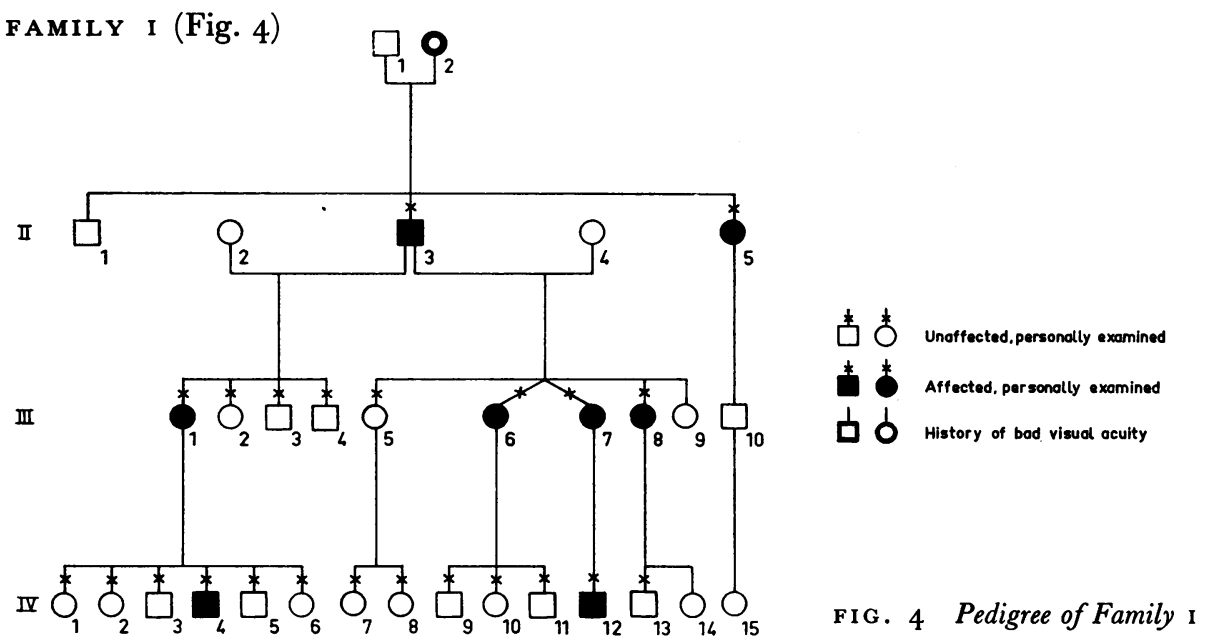

Case II.3 This man had extensive central chorioretinal atrophy of both eyes in the last years of his life. Visual acuity had been diminished to counting fingers.

Case II.5, a 79-year-old woman. The posterior poles of both eyes show confluent drusen in the papillo-foveal region. There is some pigmentation. Despice her age, the visual acuity is 0.4 , with $+\mathrm{I} .25 \mathrm{D}$ sph., $+0.25 \mathrm{D}$ cyl., axis $180^{\circ}$, in the right eye, and 0.5 , with $+0.75 \mathrm{D}$ sph., $+\mathrm{I} .5 \mathrm{D}$ cyl., axis $180^{\circ}$, in the left.

Case III.I, a 59-year-old woman. Visual acuity in both eyes is $\mathrm{I} \cdot 0$, with $+0 \cdot 25 \mathrm{D}$ sph. Both posterior poles show colloid bodies. Between these drusen a fine granular pigmentation is present. Most drusen are situated in the parafoveal region. The ocular media, discs, retinal vessels, and retinal peripheries are normal. The visual fields are full and dark adaptation is unaffected. The anomaloscope of Nagel and the Hardy-Rand-Rittler (HRR) test indicate normal colour vision.

Case III.6, a 35-year-old woman, one of identical twins, has some metamorphopsia in the right eye (Amsler test). Visual acuity in both eyes is 0.9 , with $+0.25 \mathrm{D}$ sph. in the right eye, and +0.50 D sph. in the left. The media are normal. Both posterior poles show numerous fine round, white and yellowish-brown drusen (Fig. $5 a, b$, overleaf). Some slight pigmentation is visible between the colloid bodies. The diameter of the drusen decreases from the centre of the fovea to the perifoveal area. The drusen are located in the deeper retinal layers beneath the retinal vessels. Retinal peripheries, vessels, and discs are normal. Peripheral visual fields are full but there are small relative central scotomata of about $5^{\circ}$ in both eyes. The HRR test indicates a slight red-green dyschromatopsia, while Nagel's anomaloscope reveals a slightly diminished sensitivity to red in both eyes. Dark adaptation, electroretinogram (ERG), and electro-oculogram (EOG) are normal. 

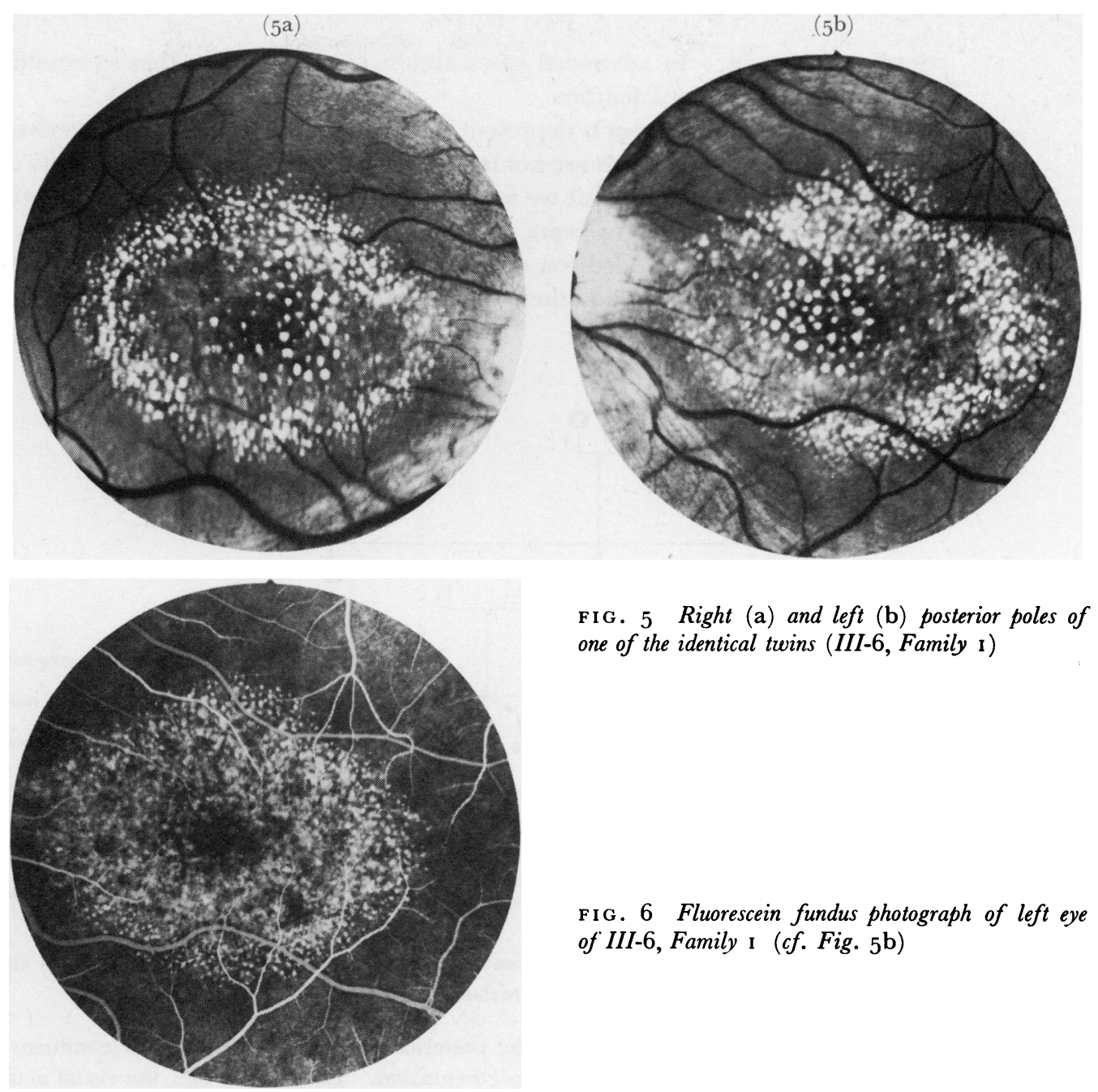
one of the identical twins (III-6, Family I)

FIG. 6 Fluorescein fundus photograph of left eye of III-6, Family I (cf. Fig. 5b)
FIG. 5 Right (a) and left (b) posterior poles of

General physical examination and routine laboratory studies reveal no abnormalities. Total lipid, triglycerides, cholesterol, lipo-proteins, and protein spectra are all normal. Fluorescein angiography (Fig. 6) shows fluorescence in the arterial phase, increasing in the venous phase. The central drusen show confluence while the perifoveal drusen remain solitary. There are more defects visible in the pigment epithelium than with normal ophthalmoscopy. The fluorescent areas persist with no change in size for 12 minutes beyond the venous phase.

Case III.7, the other identical twin, has a fundus almost identical to that of her sister (Fig. $7 a, b$ ), but with somewhat less drusen in the centre of the retina. The retinal functional tests give almost exactly the same results as in her sister: a small relative scotoma, some diminished sensitivity to red, normal dark adaptation, and normal ERG and EOG. There is some metamorphopsia in the right eye and the visual acuity is 0.9 in both eyes (emmetropic). The media are normal.

Case III.8, a 33-year-old woman, has a visual acuity of 0.6 , with $+1.25 \mathrm{D}$ sph., in both eyes. A coralliform cataract is present while the corneae are normal. The central retinae reveal a very fine granular pigmentation while, particularly in the parafoveal region, there are tiny round drusen. The retinal peripheries, vessels, and discs are normal. The visual fields and colour vision are unaffected. 

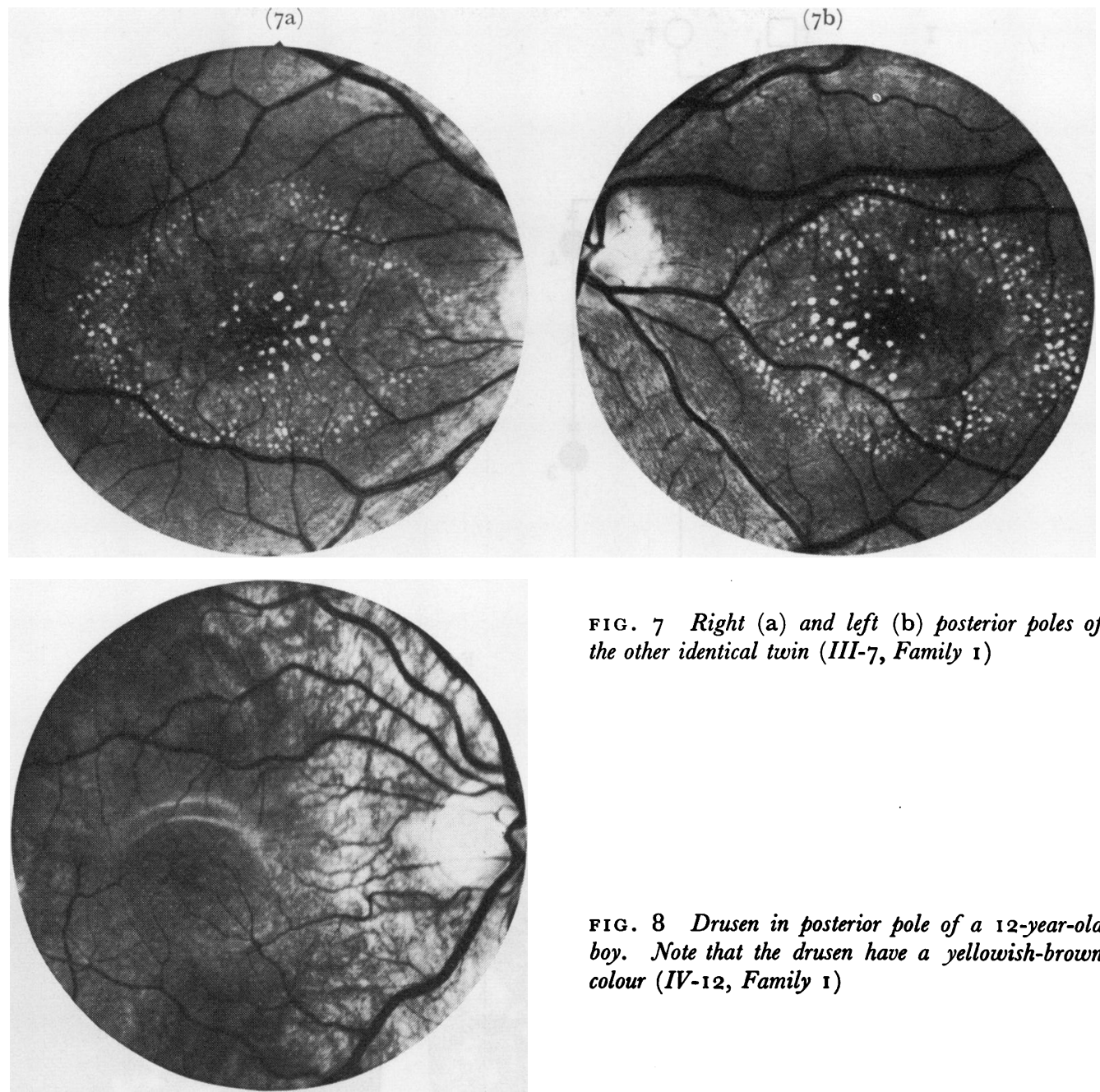

FIG. 7 Right (a) and left (b) posterior poles of the other identical twin (III-7, Family I)

FIG. 8 Drusen in posterior pole of a 12-year-old boy. Note that the drusen have a yellowish-brown colour (IV-12, Family I)

Case IV.4, a I4-year-old emmetropic boy, has a visual acuity of 0.9 in each eye. The foveal reflexes are normal but in the deeper retinal layers fine pigmentation and some yellowish-brown drusen are present. No further anomalies were found. The colour vision and visual fields are normal.

Case IV.12, a 12-year-old boy, has a visual acuity in both eyes of $\mathrm{I} \cdot 0$, with $+0.50 \mathrm{D}$ sph. There is no metamorphopsia (Amsler test). The reflexes of the fovea and foveola are normal, while there are some yellowish-brown drusen in the foveal area (Fig. 8). No further abnormalities are present. The visual fields and colour vision are normal.

FAMILY 2 (Fig. 9, overleaf)

Cases I.r and 2 The parents died when II.4 was a young girl. Nothing is known about their visual acuity.

Case I.4, a 67-year-old woman, has increasing visual complaints. The visual acuity of both emmetropic eyes is now 0.6 having been $1 \cdot 0$ one year previously. Both eyes reveal many large drusen at the posterior poles (Fig. I $a, b$ ), and also on the nasal side of the discs. Pigmentation and glistening reflexes are also seen. The discs, retinal vessels, and retinal peripheries are normal. 

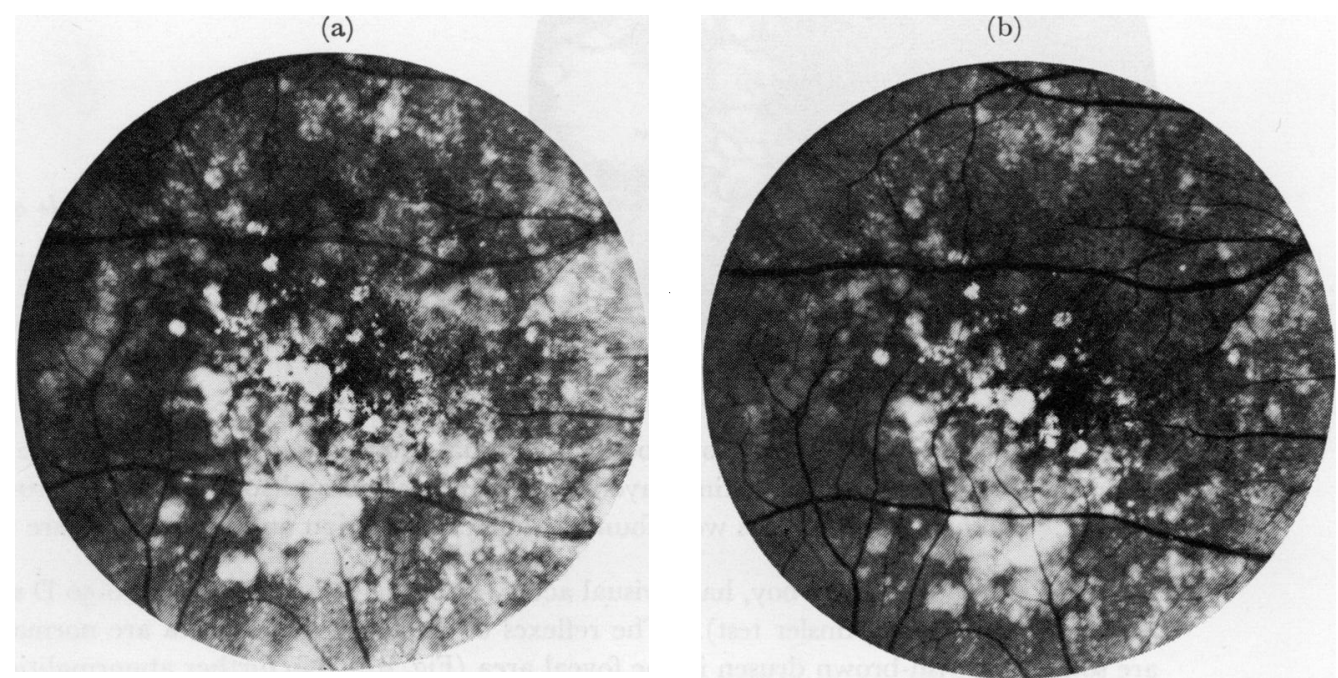

FIG. IO(a) Panchromatic photograph of drusen in a 67-year-old woman $(I I-4$, Family 2). There are more abnormal structures visible than on the orthochromatic film (Fig. Iob)

FIG. IO(b) Orthochromatic photograph of the same fundus as in Fig. Ioa

There is no metamorphopsia. The visual fields show relative central scotomata of about $8^{\circ}$. Some red-green as well as blue-yellow dyschromatopsia was found (HRR test and anomaloscope). Dark adaptation is slightly delayed, and the ERG shows subnormal scotopic and normal photopic values. The EOG is subnormal (right eye 165 per cent.; left eye 146 per cent.). General physical examination and routine laboratory tests revealed slightly disturbed liver function tests and hyperlipoidaemia. 
Case III.3, a healthy 45-year-old woman, has no complaints. Visual acuity of $\mathrm{I} \cdot \mathrm{o}$ in the right eye, with $+0.50 \mathrm{D}$ sph., and 0.2 in the left eye, with $+2 \mathrm{D} \mathrm{sph}$., $+0.75 \mathrm{D}$ cyl., axis $180^{\circ}$. The lowered visual acuity in the left eye is due to amblyopia. The ocular media and intraocular pressure are normal. The posterior poles of both eyes display large drusen with a honeycomb appearance (Fig. I I). The vessels, discs, and retinal peripheries are normal, visual fields and colour vision are unaffected. The dark adaptation and the electroretinogram are normal; the electro-oculogram, however, is subnormal (right eye 155 per cent.; left eye 164 per cent.). The technique of recording the EOG and the calculation in percentage of the light peak/dark trough ratio has been described previously (Henkes, Denier van der Gon, van Marle, and Schreinemachers, I968; Deutman, 1969).

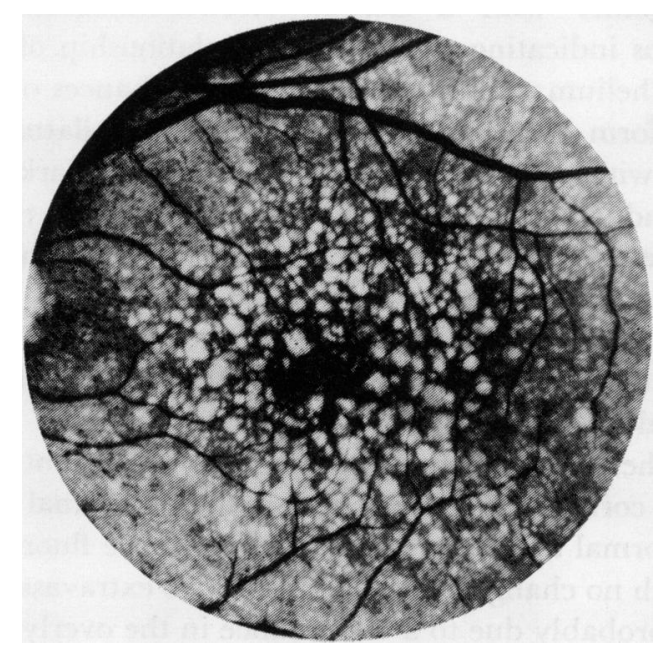

FI G. I I Drusen of Bruch's membrane arranged in a honeycomb pattern (III-3, Family 2)

\section{Comment}

In Family $\mathrm{I}$ the dystrophy is inherited in a regular dominant manner. In Family 2 the inheritance is probably dominant; so far no affected person has been found in the third generation.

The drusen present in Family I are much smaller and less extensive than those in Family 2. These differences seem to be due to variability of expression. Differences in ophthalmoscopic appearance are more frequently found in other dominantly inherited retinal dystrophies, for example vitelliform dystrophy. In heterozygotes, modifying genes may have an important influence on the expressivity of the pathological gene.

The finding of drusen in identical twins and in the posterior poles of boys aged 12 and I 4 years in Family $I$ is most interesting. In the boys most of the drusen are not white, but of a yellowish-brown colour, indicating that the adjacent pigment cells are not yet completely destroyed. The youngest affected individuals hitherto described were over 20 years of age, but Evans (1950) described a family with "crystalline retinal degeneration" which included an 8-year-old affected girl. In all probability the family described by Evans is suffering from dominantly inherited drusen of Bruch's membrane. The finding of hereditary drusen in children indicates that this dystrophy should not be classified as an adult form of "heredodegeneration of the macula" (Falls, r966).

The visual acuity remains normal for a long time but is usually diminished in advanced cases. Colour vision is normal until the fovea is affected, when a decreased sensitivity to red develops. When the destruction of the retina spreads an acquired blue-yellow dyschromatopsia may also be found. The peripheral visual fields remain full, while 
relative central scotomata develop, followed by absolute scotomata. Dark adaptation is usually normal. Pajtáš (1957), however, reported cases in which true hemeralopia was already present at the age of 14 years. The electroretinogram, being an overall response $\stackrel{\text { ㅇ }}{.}$

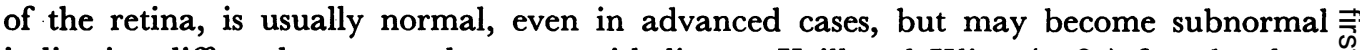
indicating diffuse damage to the neuroepithelium. Krill and Klien (1965) found only a delay in reaching an otherwise normal maximum $b$-wave.

Like the electroretinogram, the electro-oculogram is a test of the function of the $\frac{\overline{\bar{c}}}{\overline{\frac{5}{}}}$ whole retina. Drusen are situated on the inner side of Bruch's membrane and therefore $\stackrel{\mathbb{D}}{\Omega}$ tend to cause early disturbances in the pigment epithelium. In advanced cases a sub-normal electro-oculogram together with a normal electroretinogram and dark $\vec{\circ}$ adaptation is frequently found, thus indicating the important relationship of the former $\overrightarrow{\vec{H}}$ to the integrity of the pigment epithelium. In other primary disturbances of the retinal $\stackrel{\omega}{\sigma}$ pigment epithelium (e.g. in vitelliform dystrophy and fundus flavimaculatus), a patho- $\frac{}{O}$. logical electro-oculogram together with a normal or slightly subnormal dark adaptation on and electroretinogram is also found (Krill and Klien, 1965; Deutman, 1969). The or more extensive affection of the second family is expressed in the subnormal electro- $\omega$ oculogram found in the two affected women.

Panchromatic films show more abnormal structures than do orthochromatic films (Fig. 10 $a, b)$. This means that the most extensive lesions are situated mainly in the deeper $\subseteq$ retinal layers (Craandijk and Aan de Kerk, 1969).

Fluorescein angiography shows the appearance of multiple fluorescent spots during the $\vec{\varphi}$ arterial phase the outlines of which correspond to the lesions noted on normal ophthalmo- ? scopic examination, but more abnormal areas are visible. Most of the fluorescent areas persist beyond the venous phase with no change in size. There is no extravasation of dye; the visibility of the drusen is most probably due to a disturbance in the overlying pigment epithelium causing increased visibility of the underlying choroidal fluorescence (Ernest and Krill, I966). The persistence of fluorescence after the dye has disappeared from the retinal vessels may be due to staining of the drusen (Rubinstein and Paton, 1966), but it may also be due to the normal capillary tissue fluid exchange, in which fluorescein permeates to the intercapillary space, which is visible in the case of pigment epithelium defects.

Histologically, drusen consist of round accumulations of hyaline within the pigment epithelium. These hyaline bodies are continuous with the inner layer of Bruch's membrane (Treacher Collins, I913; Wolter, 1957, 1959; Forni and Babel, 1962; and others). In the initial stages the choroid and neuroepithelium are normal, but in advanced stages $\delta$ a considerable atrophy of these structures is found in the posterior pole of the eye. This dystrophy probably originates in an inborn error of metabolism, situated mainly in the $\stackrel{\bigcirc}{工}$ retinal pigment epithelium. This can be concluded from the observations of Wolter $\frac{T}{0}$ (1957), who found two different developmental types of drusen:

(I) By accumulation of hyaline substance within slowly degenerating cells of the pigment epithelium;

(2) By extracellular deposition of hyaline substance beneath the pigment epithelium on Bruch's membrane.

Both types of drusen occur together and both finally result in the large hyaline formations $\stackrel{\oplus}{\oplus}$ on Bruch's membrane with the complete destruction of the adjacent pigment cells. As 0 the choroid and the neuroepithelium are normal in early stages, we may assume that the $\stackrel{+}{\mathbb{P}}$ pathogenesis in dominant drusen is a primary dystrophy of the cells of the pigment $\stackrel{D}{\mathscr{D}}$ epithelium. Further support for this concept is given by Klien and Krill (1967) who 
found almost identical retinal function profiles and fluorescein patterns in cases of fundus flavimaculatus. By means of histological examination of an eye with fundus flavimaculatus they proved that the primary affection is located in the cells of the pigment epithelium.

The transmission of drusen of Bruch's membrane is autosomal dominant, usually in a regular manner (Pearce, 1967). General physical examination and routine laboratory tests generally show no abnormalities.

The differential diagnosis is between non-hereditary drusen and other hereditary dystrophies which display white flecks in the retina. Fundus flavimaculatus and fundus albipunctatus are such dystrophies and have a retinal function profile almost identical to dominant drusen. For this reason Krill and Klien (1965) grouped these conditions together under the title of "flecked retina syndrome".

In Stargardt's disease, which has to be differentiated from dominant drusen, many white flecks may be present at the posterior pole. This condition may be indistinguishable from fundus flavimaculatus when the latter is complicated by a foveal dystrophy. Retinitis punctata albescens and Bietti's tapeto-retinal dystrophy with marginal corneal dystrophy (Bagolini and Ioli-Spada, 1968) also present a white flecked retina.

Kandori's "fleck retina with congenital hemeralopia" might be yet another distinct entity, although Klien and Krill ( 1967 ) supposed that the cases described by Kandori, Setogawa, and Tamai (1965) might possibly fit into the fundus flavimaculatus category. This is doubtful, however, because congenital hemeralopia is not found in fundus flavimaculatus, and furthermore the flecks described by Kandori and others (1965) are much bigger than the small fishtail lesions found in fundus flavimaculatus (Kurimoto and Fukunaga, 1969). Capillarosis and "focal choroidopathy" (Yeates, 1960) show very tiny white flecks and are therefore easily differentiated.

\section{Summary}

In one family there were eight individuals with dominantly inherited drusen of Bruch's membrane, including a pair of identical twins and two boys aged 12 and 14 years.

In a second family the same condition was found in a mother and her daughter.

The interfamilial differences in the ophthalmoscopic appearances of this dystrophy are stressed. As Doyne's honeycomb dystrophy and malattia leventinese are indistinguishable entities and therefore probably due to the same gene, it is proposed to use the term "dominant drusen of Bruch's membrane" for this condition. Thus the complicated nomenclature of Tay's choroiditis, Holthouse-Batten's choroiditis, Doyne's honeycomb choroiditis, and malattia leventinese can be avoided.

It is assumed that this is a primary dystrophy of the cells of the retinal pigment epithelium.

Mr. A. L. Aan de Kerk took the photographs, Dr. A. Craandijk M.D. provided the fluorescein photograph, and Mrs. L. H. M. van Duyn prepared the manuscript.

This investigation was supported by the Netherlands General Association for Prevention of Blindness and the Organization for Health Research TNO.

\section{References}

BAgOlini, B., and IOli-SPADa, G. (1968) Amer. 7. Ophthal., 65, 53

COLLINS, E. TREACHER (I9I3) Ophthalmoscope, I1, 537

GRAANDiJK, A., and AAN DE Kerk, A. L. (ig69) Brit. J. Ophthal., 53, 568 
Deutman, A. F. (1969) Arch. Ophthal. (Chicago), 81, 305

DOYNe, R. W. (1899) Trans. ophthal. Soc. U.K., 19, 71

(1910) Ibid., 30, 93

DUKE-ELDER, S. (1967) “A System of Ophthalmology", vol. 1o. Kimpton, London

ERNEST, J. T., and KRILL, A. E. (1966) Amer. F. Ophthal., 62, I

EVANs, P. J. (1950) Trans. ophthal. Soc. U.K., 70, 96

falls, H. F. (1966) Trans. Amer. Acad. Ophthal. Otolaryng., 70, I034

FORNI, s., and BABEL, J. (1962) Ophthalmologica (Basel), 143, 3 I 3

FRANCESGHETTI, A., FRANçOIS, J., and BABEL, J. (1963) "Les hérédo-dégénérescences chorio-

rétiniennes". Masson, Paris

FUCHs, A. (1956) Amer. F. Ophthal., 4I, 840

HENKES, H. E., DENIER VAN DER GON, J. J., MARLe, G. W. VAN, and SGHREINEMAGHERS, H. P. (1968)

Brit. F. Ophthal., 52, 122

hOLthouse, E. H., and BatTen, R. D. (1897) Trans. ophthal. Soc. U.K., 17, 62

hUtchinson, J., and tay, w. (1875) Roy. Lond. ophthal. Hosp. Rep., 8, 231

KANDORI, F., SETogawa, T., and tamai, A. (1966) In "Retinal Degenerations ERG and Optic

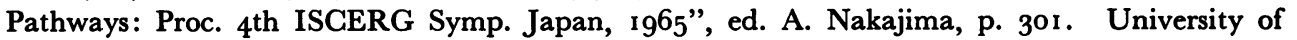

Tokyo, Tokyo

KLAINGUti, R. (1932) Klin. Mbl. Augenheilk., 89, 253

KLIEN, B. A., and KRILL, A. E. (1967) Amer. F. Ophthal., 64, 3

KRILl, A. E., and KLIEN, B. A. (1965) Arch. Ophthal. (Chicago), 74, 496

KURImoto, s., and fUKUnAGA, K. (1969) Yonago Acta med., 13, 123

LORENTZEN, s. E. (1966) “Drusen of the Optic Disk", Acta ophthal. (Kbh.), Suppl. 9o. Munksgaard,

Copenhagen

PAJTÁš, J. (1957) Ophthalmologica (Basel), r34, 101

PEARCE, w. G. (1967) Ann. hum. Genet., 31, 173

(1968) Brit. 7. Ophthal., 52, 73

RUBinstein, K., and PATON, A. (1966) Trans. ophthal. Soc. U.K., 86, I 39

sEITz, R. (1968) Ber. dtsch. ophthal. Ges., 68, Zusammenkunft, Heidelberg, 1967, p. 373

- and kersting, G. (1962) Klin. Mbl. Augenheilk., 140, 75

voGT, A. (1925) "Die Ophthalmoskopie im rotfreien Licht", in "Graefe-Saemisch Handbuch der

Gesamten Augenheilkunde", vol. 3, p. I. Springer, Berlin.

WAARDENBURG, P. J. (1948) Ophthalmologica (Basel), 115, II5

WOLtER, J. R. (1957) Klin. Mbl. Augenheilk., 130, 86

(1959) A.M.A. Arch. Ophthal., 6r, 127

yeATES, F. м. (1960) Trans. ophthal. Soc. Aust., 20, 96 